ARTICLE

\title{
Skilled Labor Force as a Cornerstone of Entrepreneurial Economic Development - International Experience for Georgia
}

\author{
SHATAKISHVILI, Davit ${ }^{a}$ \\ a. Individual researcher, Tbilisi, Georgia. \\ Correspondence to (Shatakishvili95@gmail.com)
}

\section{PUBLISHED: 26/10/2021}

Accepted: $25 / 10 / 2021$

Submitted: $21 / 10 / 2021$

\section{COPYRIGHT NOTICE:}

\section{CITE THIS PAPER:}

Shatakishvili, Davit (2021). "Skilled Labor Force as a Cornerstone of Entrepreneurial Economic Development International Experience for Georgia" Journal of World Economy: Transformations \& Transitions (JOWETT) 1(02):05. DOI: https://doi.org/10.52459/jowett1251021

\begin{abstract}
Labor force is utterly significant factor through which a product or service is created in any country. Consequently, the quality of the labor force is directly proportional to the entrepreneurial economic development, service standards and steady, dynamic growth as a whole. Proficient workforce has an ability to solve problems and efficiently adapt to changes in an ever-evolving world. It contributes to the development of the country's domestic production, as well as plays an important role in attracting foreign direct investments. The following paper outlines the importance of a qualified and skilled labor force for entrepreneurial economic progress and analyzes its various aspects. Additionally, in this regard, the study delineates current challenges in Georgia and examines the best examples of international practice. Finally, based on multifactorial analysis, the paper presents solutions and recommendations to solve existing problems, for long-term stable economic betterment.
\end{abstract}

\section{KEYWORDS}

Labor Force, Capacity Development, Economic Growth, Entrepreneurship, Unemployment 


\section{The Role of Skilled Labor Force in Economy}

Nowadays, the labor force is quite diverse and covers raft of specialties. Along with the development of latest technologies, new professions are becoming demandable, and at the same time obsolete ones are being erased. The nation, that has unique professionals in various fields, sees numerous kinds of economic and social benefits. In a burgeoning world, the demand for qualified specialists tailored to the needs of the modern market is growing progressively. Consequently, the mobility of skilled labor forces has become one of the main factors of competition between the countries. Any development-oriented state wants to base its production and services on people who will guarantee nation's long-term success. Therefore, the process of talent outflow from the country has a direct adverse impact on the production capacity, jobs and stable operational development.

The labor force is quite vulnerable to internal and external economic shocks. It is influenced by the supply-demand ratio, population size, taxes, reimbursements and more. For instance, rapid economic expansion and, consequently, growth in demand are creating new job opportunities, while a shrinking economy is having a reversible effect on similar indicators. The vulnerability of the labor force is further reflected in the fact that it is affected by both the private and civil society sectors, as well as the state has a major role to play. The private and civil sectors act according to their own needs and requirements, while the state has a more critical function. The role of the national government is mainly demonstrated in the regulations for employees and the unemployed, in setting the minimum wage, commercial activity taxes, as well as in income and property taxes of individuals, special supporting programs, legal framework and others. Therefore, the steps of the governments have a direct impact on the job-creating sectors in the country.

Definitely, job creation process in the country is extremely important, however it is more essential to have skillfull specialists. The quality of the workforce plays a key role in promoting civil liberties, political and economic stability, reducing criminal and corruption risks, developing sustainable investment and economic policies, enlarging entrepreneurship, innovations and general social prosperity of the nation (OECD, 2006). That is why the lack of a skilled workforce deprives the country plenty of potential opportunities, benefits and advantages.

Not surprisingly, high job standards and employee qualifications are one of the most principal determinants of potential location for international investors. The development of a sound investment climate in the country depends on multiple factors, such as ease of doing business, stable political and economic environment, taxes, free trade agreements, business globalization, judiciary system, level of crime and more. However, here we must emphasize - qualified labor force, which is extremely attractive to potential investors. This is an opportunity for them, to produce a product or service without additional costs that may include retraining and learning. Ultimately, a qualified and skilled workforce creates the country's core wealth and contributes to sustainable economic progress (Arghutashvili, 2018). It increases productivity, saves costs, solves 
problem and so forth. The relationship between investments and labor force standards was first studied by the Organization for Economic Co-operation and Development in 1996, where the connection between them was revealed. Since then, all research confirms how substantial is a skilled workforce in attracting foreign direct investments to the country $(\mathrm{OECD}, 2006)$.

The quality of the labor force depends on important factors such as education, access to training programs, physical activity and health status. Education and access to training can be considered as a capital investment that provides stable and long-term results.

People with highly developed skills create new job opportunities, have more creativity resources, and contribute to an overall increase in job satisfaction. The advantages of investing in high quality education and vocational programs can be presented as following:

- Encourages people to use their exhaustive potential, to promote employment and social development;

- Increases the productivity of both employees and enterprises;

- Makes a significant contribution to the development of innovations, new technologies and production capabilities;

- Encourages domestic, as well as foreign direct investments, thus leads to increasing jobs and reducing unemployment;

- It plays a vital role in increasing wages and eliminating social inequality.

Effective communication between the government, workforce, private sector and educational institutions is crucial. Comprehensive access to education and various vocational programs removes any barriers between the poverty and wealth, education and illiteracy, high and low social status, ethnic or vulnerable groups and so forth (International Labor Office, 2010).

\section{"Skills Gap" in Georgia}

Since gaining an independence, the issue of employment and the labor force qualification in Georgia has been one the main challenges of the nation. Despite some reforms, the country is still unable to solve the unemployment difficulties (ETF, 2017). Additionally, it is accompanied by a serious failure in workforce qualification, that is one of the major challenges not only for local but for foreign investors as well. The unskilled workforce is one of the main obstacles to new job creation process, that also affects the overall unemployment rate. In Georgia, the problem of labor skills and qualifications has several main causes, and all these factors are interconnected: 
- Fundamental problems in secondary and higher education. The country's educational system finds it difficult to adapt to modern market demands and equip students with the necessary skills. Additionally, harmful practices have been established in the country, and people, despite their diligence and motivation, still enter the higher educational institutions. This in turn leads to fewer students in vocational schools. This approach results in the fact that such people can neither get the desired education nor use professional entities;

- Due to the above-mentioned reason, it becomes difficult to develop vocational educational institutions at appropriate level. Thus, currently, such institutions find it difficult to provide students with the skills and knowledge that satisfy the market demands;

- Underdeveloped labor market is one of the leading causes of low skilled labor force. On the one hand, companies are less concerned with raising the employee qualifications, on the other hand, there are fewer high-level technical enterprises where knowledge has to be acquired and transferred to new workers;

- Lack of communication between the government, private sector and educational institutions leads to confusion of interests and priorities, which ultimately has a detrimental effect. It is essential for the educational sector to have a research-based guideline on labor market requirements that needs to be developed in conjunction with the private sector;

- The country has an underdeveloped scientific field, as well as there is no relevant laboratories, equipment and infrastructure. Existing situation becomes an important impediment to innovations, new technologies and production development;

- One of the most significant problems facing the country is "Brain Drain". A lot of talented people who have got higher and scientific education in the world's leading universities are reluctant to leave the country since they do not have an appropriate working conditions, remuneration and promising perspectives. All this leads to a static condition of the country, that means a reversal in a dynamic and changing world;

- The state-supported short-term training programs are undeveloped in the country. Moreover, there is no regional and municipal retraining infrastructure that would allow local community to deepen their skills and professional expertise;

- Due to the underdeveloped private sector in the country, the number of people working in governmental entities is quite high. All these increases budget expenditures and at the same time, less attention is paid to specific skills and other priority areas. The small model of public governance promotes the development of the business sector, as well as more rational spending of state funds, including more attention to educational and vocational teaching.

Figure 1 shows the level of unemployment in Georgia for the last ten years, based on the data of the National Statistics Office of Georgia (NSO, 2020). 
Figure 1. Unemployment Rate in Georgia (2010 - 2020)

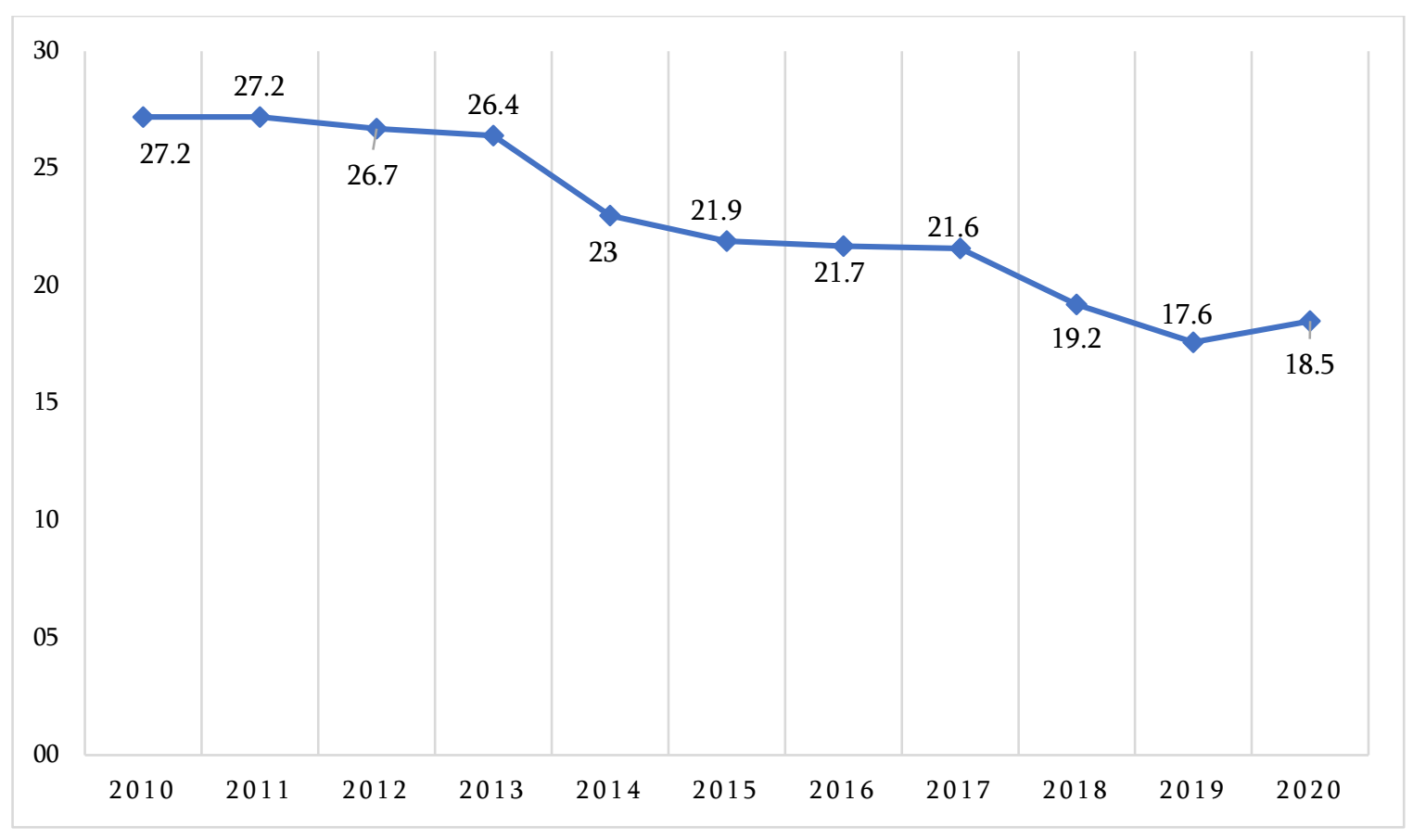

In 2018, the Ministry of Economy and Sustainable Development of Georgia conducted a survey, in order to identify the problems, business entities face regarding to the workforce recruitment. The study also aimed at in-depth analysis of the labor market, relevance of professional skills with modern market demands, special inquires for concrete expertise and determining the attitude of employers towards specific difficulties. This research has clearly identified labor challenges in Georgia and we have an opportunity to discuss some of them to see the problem broadly.

Figure 2. Number of Employees by the Level of Education

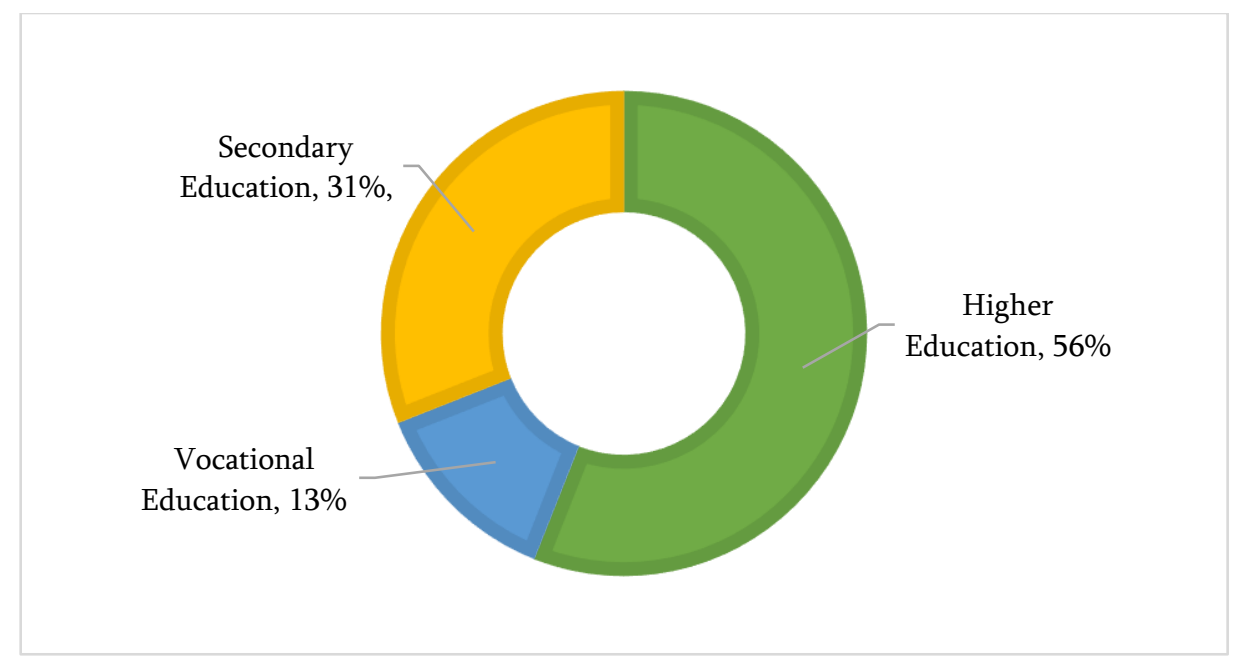


First of all, the most important issue is the level of education. As it can be seen from the Figure 2, made by the author, based on the data collected from the Ministry of Economy and Sustainable Development of Georgia (MESD, 2018), the smallest share of employment comes from vocational education, that is a noteworthy fact, meaning practically underdeveloped professional schools.

\section{Figure 3. Obstacles for Employers when Hiring}

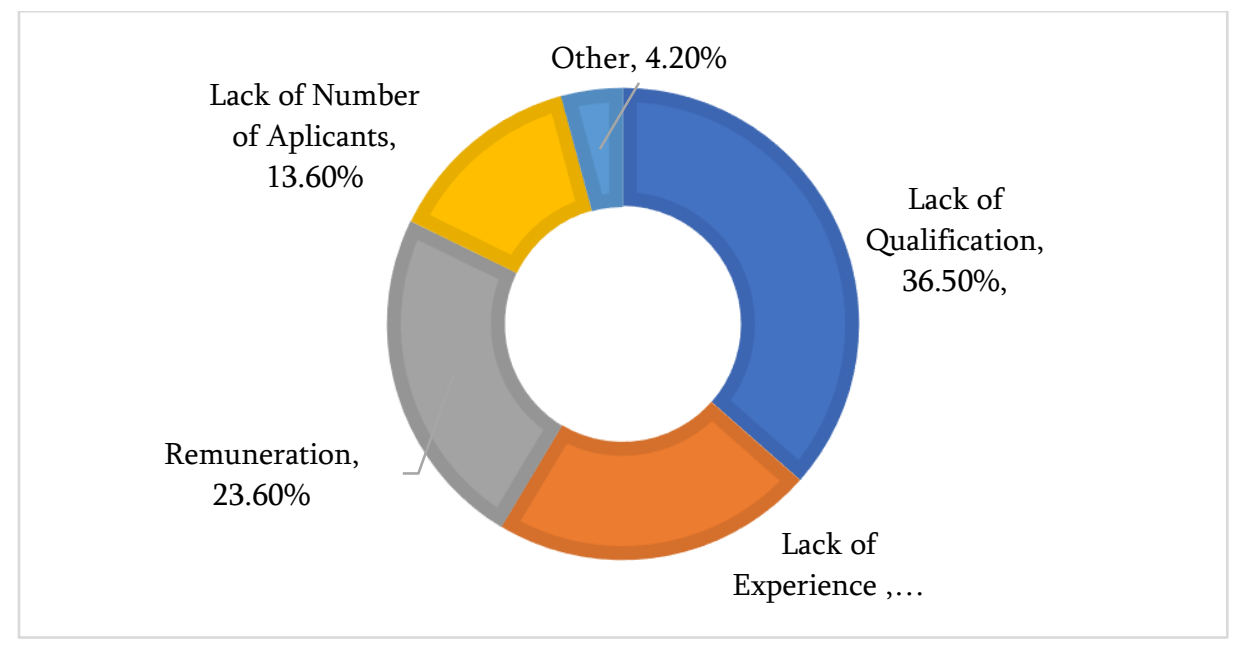

The study identified a problem that is the biggest challenge employers face when hiring a new employee, it is a lack of candidate's qualification, represented on the Figure 3 (MESD, 2021). This is of course due to the fundamental causes we have already discussed above. Here, an important problem is the lack of experience, which is directly linked to the undeveloped private sector. Experience leads to the improvement of professional skills and, conversely, the acquisition of new adroitness in practice leads to the accumulation of expertise. A noticeable share is hold by getting fewer applications, although lower job skills and experience directly lead to restraint from job seekers. 


\section{Figure 4. Lack of Skills of the Applicants}

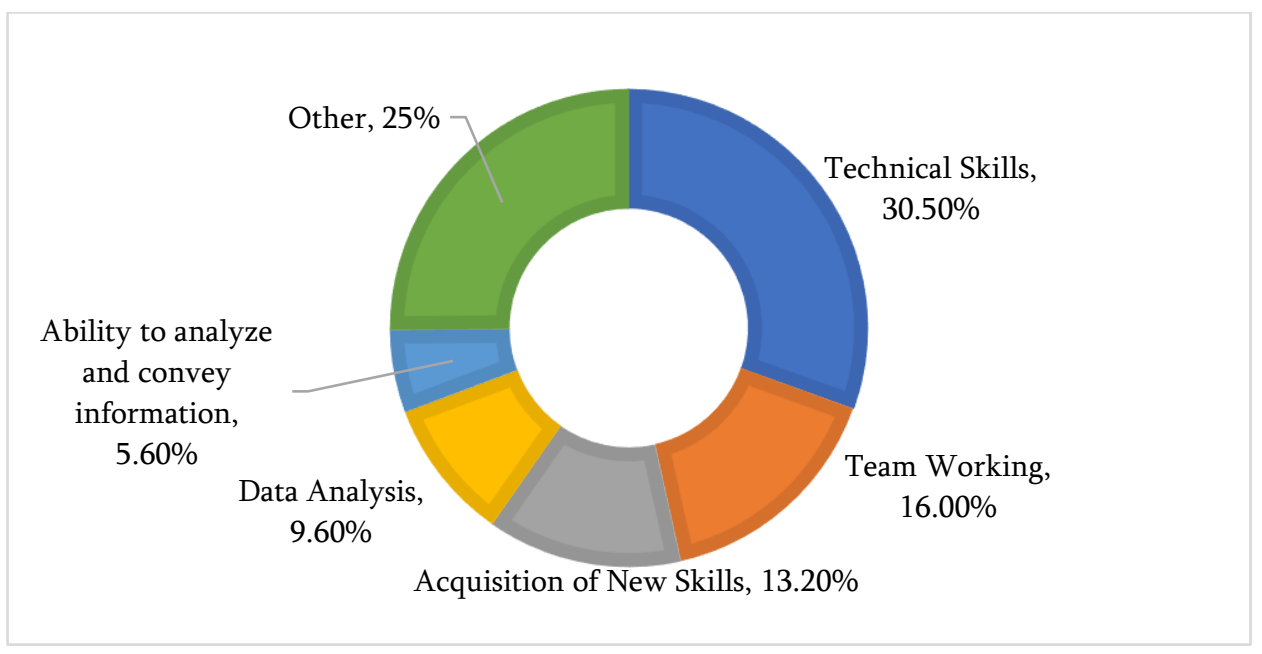

One of the fundamental issues identified by the study is the lack of skills such as technical, data analysis, communication and teamwork abilities, as it is illustrated on the Figure 4 (MESD, 2018). This once again confirms the weaknesses of educational institutions that fail to equip a potential workforce with critical abilities.

\section{Figure 5. Basic Measures to Overcome Skills Problems}

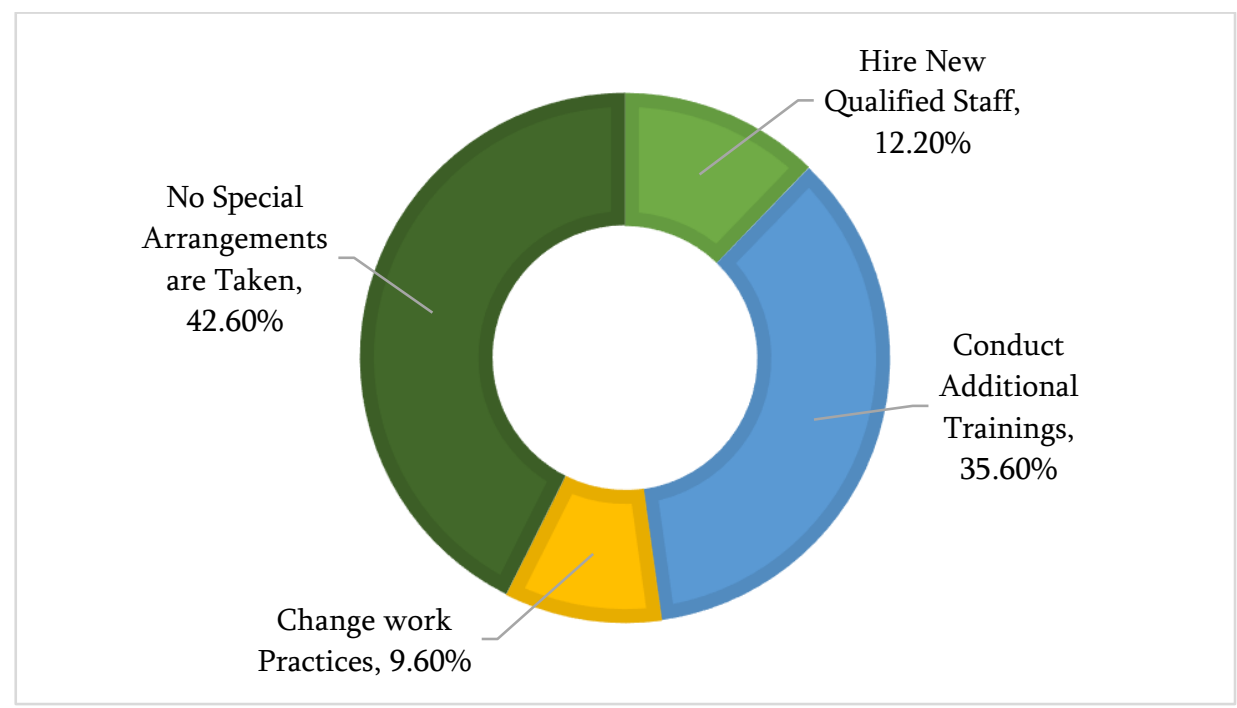

A noteworthy issue is the effort assessment of business entities regarding to the existing challenges. According to the study, the Figure 5 (MESD, 2018) displays that only 5\% of the business organizations surveyed had participated in training sessions during the previous one year. Almost $43 \%$ of companies do not 
take effective steps to deal with problems. In many cases, companies prefer to spend resources on a new employee recruitment or simply change their approach to the issue. This leaves less space for workforce development.

Figure 6. Government and Private Sector Employee Ratio in Georgia (2020)

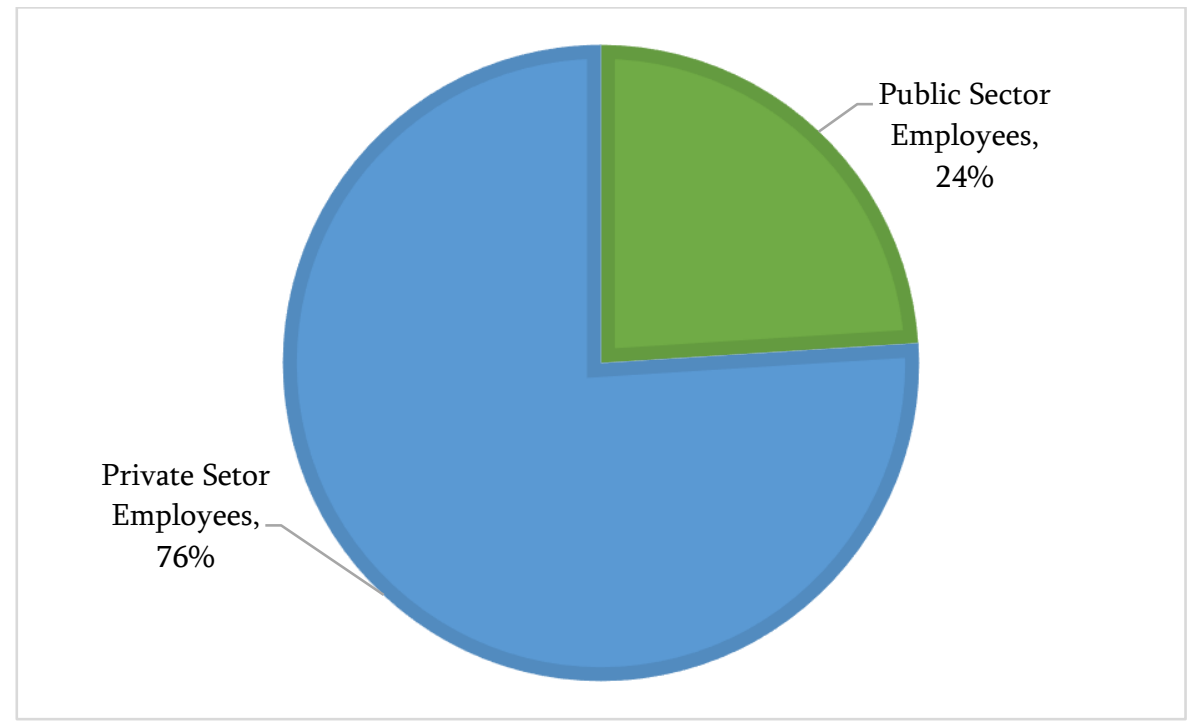

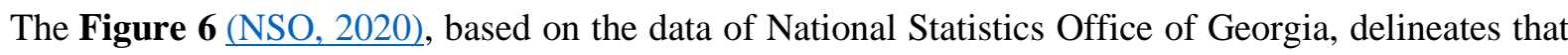
the share of public sector employees in the country is quite high. Large state bureaucracies are enforced to employ more people in the governmental bodies. This fact is also explained by the undeveloped business sector. The high dependence of employees' public sector leads to a lack of activity in private companies, as well as challenges in labor force capacity.

In order to overcome this problem, the Government of Georgia implements certain professional programs, however, it is more local in nature and serves to increase the qualifications of people already employed. For instance, government agencies that assist small and medium-sized businesses (in this case, the Ministry of Economy and Ministry of Agriculture) offer beneficiaries training and retraining programs in the specialties considered by the grant or subsidize projects. Although this benefit applies to certain individuals, in order to do their business better, unfortunately it does not solve fundamental problems that has much more fathom roots.

The problem of labor qualification in Georgia directly affects foreign direct investments. In almost all international organizations' reports, where the country's investment climate and opportunities are discussed, investors outline that labor skill is one of the main difficulties (Charaia \& Lashkhi, 2019). Workforce is the 
fundamental source that creates a products and services. In this case, since it is a cardinal problem, investors are not worth investing in this country. Consequently, a seemingly uncomplicated problem finally causes raft of difficulties, that has long-term adverse outcomes and explicitly affects the socio-economic environment of the country.

\section{International Experience of "Upskilling"}

Individual characteristics of the countries, such as socio-economic climate, demographic situation, political circumstances and etc., push countries to develop their own strategies for human development. In this regard, it is inherently significant to determine the relevance of the workforce skills to the country's priority sectors. Additionally, it is necessary to identify the professions and skills that the country will need in the medium- and long-run period. In terms of the talent development, there are several main directions:

- Children - an independent upbringing from the rudimentary stage of education, freedom of thought and an environment that will help them grow up as free thinkers, without clichés and restrictions;

- Young people - their adaptation to the market demands, equipping them with the necessary skills and providing access to opportunities, which will help them to successfully transform themselves from higher or vocational educational institutions into a working mode;

- Adults and older people - maintaining them, which is essential for future generations to transfer relevant knowledge, expertise and know-how, enhancing their competence and using them as a unique opportunity for youngsters towards further development.

The world experience in terms of skilled labor is quite diverse. Each country tries to find its own way that will suit the local challenges. In this regard, Denmark, Sweden and Switzerland are examples of the world's leading countries, that we can discuss as best practices. Each of them combines a systemic attitude, in which all parties are actively involved, as governmental institutions, also business and educational entities (Ministry of Employment and Economy of Finland, 2012). We can present this approach in a few key points:

- The country has created a system that allowed labor market demand-supply to be assessed, and appropriate proactive decisions to be made;

- The government has actively supported the business sector to care about raising the expertise and skills of its employees;

- The state enabled an admission of skilled immigrants and created suitable conditions for them;

- The government has developed policy documents that have promoted gender balance, equal opportunities and a non-discriminatory approach; 
- The country has actively managed human resources development in the field of science and technology.

\section{Denmark}

The Danish labor market is quite diverse. It is characterized by high participation level of citizens in the labor process, as well as gender balance. According to 2019 data, the unemployment rate in Denmark was $5.2 \%$ (Statista, 2020-a). Danish success story is due to several fundamental factors. Primarily, it is an educational system that is structured and adapted to the modern market demands, that includes both school and higher education. Along with vocational education and continuing training system (European Center for Development of Vocational Training, 2012).

According to the IMD World Talent Ranking (IMD, 2020), Denmark spends $6.4 \%$ of its Gross Domestic Product (GDP) on education. Higher and professional education is a priority for the country. In addition, the private sector is actively involved in the on-job-training process. Caring about employee qualifications is one of the preferences for the companies. Moreover, it is important for business entities to attract talents and reimburse correspondingly (OECD, 2012). In addition, Denmark has properly developed workforce motivation systems. Besides, the country has one of the highest rates for university education to meet market requirements, which is $8.83 / 10$.

In Denmark, labor force is a state-level priority. Thus, there is a governmental entity - The Danish Agency for Labor Market and Recruitment, that ensures the monitoring of the labor market, the identification of trends and the preparation of relevant policy documents. Furthermore, it provides individual consultations for the unemployed people, that leads to highly productive results. The state analyzed that unemployment benefits without proper criteria caused unemployed people to stay at the same stage, therefore, they created a system that helps unemployed people if the appropriate conditions are met, and it is not uncontrollable. Therefore, a high level of cooperation between the governmental entities, the private sector and the citizens, as well as a thoughtful state policy in this direction will ensure high results, that is inevitably reflected in economic well-being.

\section{Sweden}

Sweden is one of the leading countries in terms of skilled labor. According to the IMD World Talent Ranking (IMD, 2020) the country spends $6.9 \%$ of its GDP on education. The state pays special attention to both school and higher education, as well as professional skills development. The private sector is also actively involved in this process, the main priority of which is to cherish the qualifications of the employees. According to 2019 data, the unemployment rate in Sweden was 6.83\% (Statista, 2020-b). 
Sweden's success in terms of skilled labor force is due to a number of fundamental issues that have emerged as a result of recent reforms: the state unemployment insurance system has changed, state budget finances for adolescents and higher education have increased, science and technology has become a national priority, municipal support has increased and changed the approach to immigrants who were distinguished by the highly skilled professional activities. The state implements special support programs for young people, which ensures their professional development and integration into the working process. Additionally, the priority is to maintain the regional balance in order not to gather skilled workers in one place, and in this regard, the involvement of the state is essential, that contributes to allocation of human resources regionally.

\section{Switzerland}

Switzerland is one of the most successful, stable and economically strong countries in the world. Consequently, it is not surprising that it is also distinguished by a skilled and capable workforce (World Economic Forum, 2019). According to 2019 data, the unemployment rate in Switzerland was 4.39\% (Statista, $\underline{2020-\mathrm{c})}$. The country is eminent for a quality higher and vocational education system, as well as on-job-training opportunities by the companies. According to the IMD World Talent Ranking 2020 the state spends 5.6\% of its GDP on education. All this is of course is due to the relevant legal and economic framework. Switzerland has quite an interesting experience in this regard. For example, more than $70 \%$ of schoolchildren participate in the "Gold Standard: vocational education training system. In many cases, young people after 17 years old are involved in professional seminars of business companies, where they receive both remuneration and vast knowledge and experience. As a result, the country acquires a capable labor force in 3-4 years who can take the job responsibilities and operate productively. This proficiency and experience make Switzerland a stand out nation in the world for the quality of its products or services. It is important that the private sector is fully involved in retraining, that is the largest source of economic development and state budget revenues.

\section{Results and Recommendations}

In Georgia, equipping the workforce with relevant skills is a long-term process, although tangible results can be achieved even in the medium-term period. This process will allow the country to create an important basis for the entrepreneurial economic development, that will be favorable for both domestic and international investors. Reforms should include the following areas:

- Fundamental reforms should be implemented in secondary and higher educational systems based on international experience. This will promote pupils to think unbound and be free from clichés. Moreover, adaptation of university education to the modern market demands is crucial. This will 
provide various opportunities for students to do more practical work and internships. More applied work means more skills and experience;

- It is necessary to take the vocational educational system to a new stage of development and increase its popularity. School students should be given an access to professional programs, many of which may be involved in the industrial educational process;

- The state should make the science and technology development as a top priorities. It is pivotal to create an appropriate infrastructure in the country - laboratories, testing facilities, research centers, scientific equipment and instruments and more;

- The state should be actively involved in the labor market monitoring process and have active communication with the private sector and educational institutions. This will let the country to identify the professions in demand on the market, and this is where the state has to assign its resources and efforts;

- It is decisive to establish vocational training centers in the regions, which will enable the local community of municipal cities and villages to acquire the necessary skills and knowledge. People who work in small enterprises, are self-employed or are engaged in agricultural activities, should have an access to professional training and retraining programs. The regions need to identify the potential for development in specific areas, create a suitable learning infrastructure and give people the opportunity to learn and progress;

- Individual and direct negotiations with domestic and foreign investors are crucial in order to assemble large investments in the country. The state should take responsibility for retraining and equipping potential staff with relevant skills and knowledge by the needs of investors;

- The state has to assist the private sector in organizing training and retraining programs. The country should create a standard in this direction, in which companies will be involved. It is important for the business sector to feel supported by the state in order to have the motivation to retrain people and get more qualified staff;

- The state ought to care about the students, to get proper education in top academic institutions and should take responsibility for young people who have been educated in leading universities around the world, offer them adequate working environments and conditions that will allow them to apply acquired expertise in their homeland;

- Along with the strengthening of the private sector, it is necessary for the state to think about the concept of small government, which will let the country to assign budget funds to more priority areas;

- The government has to reconsider its unemployment and social assistance policies, which in many cases becomes an impediment for people to start working and they prefer to stay on the state assistance.

The above-mentioned reforms should yield tangible results in the medium-term period, although in the long run its fecundity will be more apparent. All this will allow the country to accumulate knowledge and 
experience. This means more innovation, technological development and the general progress of the entrepreneurial economy. Georgia remains a country of consumer economy, one of the hindering factors of which is the unskilled labor force. Therefore, starting reforms from the ground up will be an important step towards breaking the locked circle.

FUNDING: The author did not receive any external funding.

CONFLICT OF INTEREST: The author declares no conflicts of interest.

\section{REFERENCES}

1. Arghutashvili V. (2018). Tbilisi State University. DSpace Repository. The Challenges of Tourism Industry in Georgia. Retrieved from https://dspace.tsu.ge/handle/123456789/466?locale-attribute=en

2. Charaia V.; Lashkhi M., (2019). CA\&C Press AB. An Analysis of the Motives Underlying Foreign Direct Investments (The Case of Georgia). Retrieved from https://www.cac.org/online/2018/journal_eng/cac04/07.shtml?fbclid=IwAR0MI_u_gj578WbKicC4c_bO9Mken282CnOnu3naEltWDohe_WaS2RGg wKg

3. ETF (European Training Foundation), (2017). Skills Mismatch Measurement in Georgia. Retrieved from https://www.etf.europa.eu/sites/default/files/201910/skills_mismatch_measurement_georgia.pdf

4. European Center for the Development of Vocational Training, (2012). Vocational Education and Training in Denmark. ISBN 978-92-896-1085-8. DOI: 10.2801/69492. Retrieved from https://www.cedefop.europa.eu/files/4112_en.pdf

5. IMD, (2020). IMD World Competitiveness Center, World Talent Ranking. Retrieved from https://www.imd.org/centers/world-competitiveness-center/rankings/world-talentcompetitiveness/

6. International Labor Office. (2010). A Skilled Workforce for Strong, Sustainable and Balanced Growth. Retrieved from https://www.oecd.org/g20/summits/toronto/G20-Skills-Strategy.pdf

7. MESD (2018). Ministry of Economy and Sustainable Development of Georgia, Statistical survey of enterprise demand for skills. Retrieved 
from http://www.lmis.gov.ge/Lmis/Lmis.Portal.Web/Handlers/GetFile.ashx?Type=Survey\&ID=0e5 d2e14-f30c-451c-8df9-335626974ad3

8. Ministry of Employment and Economy of Finland, (2012). Labor Market Reforms and Performance in Denmark, Germany, Sweden and Finland. ISBN 978-952-227-620-9. Retrieved from https://tem.fi/documents/1410877/3437250/Labour+Market+Reforms+and+Performance+in+D enmark+09052012.pdf

9. NSO (2020). National Statistics Office of Georgia. Retrieved from https://www.geostat.ge/en/modules/categories/37/employment-andwages and https://www.geostat.ge/en/modules/categories/683/Employment-Unemployment

10. OECD (Organization for Economic Co-Operation and Development), (2006). Chapter 8, Human Resources Development Policy. Policy Framework for Investment, A Review of Good Practices. ISBN 92-64-02586-3. Retrieved from https://www.oecd.org/daf/inv/investment-policy/40287406.pdf

11. OECD (Organization for Economic Co-Operation and Development), (2012). Human Resources Management Country Profiles Denmark. Retrieved from https://www.oecd.org/gov/pem/OECD\%20HRM\%20Profile\%20-\%20Denmark.pdf

12. Statista (2020-a). Denmark: Unemployment rate. Retrieved from https://www.statista.com/statistics/586271/monthly-unemployment-rate-in-denmark/

13. Statista (2020-b). Sweden: Unemployment rate. Retrieved from https://www.statista.com/statistics/375284/unemployment-rate-in-sweden/

14. Statista (2020-c). Switzerland: Unemployment rate. Retrieved from https://www.statista.com/statistics/263707/unemployment-rate-in-switzerland/

15. World Economic Forum (2019). Switzerland has the Most Highly Skilled Workers in the World. Retrieved from https://www.weforum.org/agenda/2019/10/switzerland-economy-skills-workforcecompetitive/ 